\title{
Why should surgery for early-onset strabismus be postponed?
}

\author{
M DELLER
}

From the University Eye Hospital, Lausanne, Switzerland

SUMmARY The author presents a continued study of 82 cases of pseudoparalysis of the bilateral rectus muscles in early-onset convergent strabismus following early surgery. Up to 10 years after surgery motor results show that $72 \%$ of cases remain within \pm 10 prism dioptres after a single surgical procedure. Sensorial findings corroborate the results of other authors' studies in that binocular association is only achieved in those patients where surgery was carried out at a very young age, not older than 1 year. Surgical procedures consisting of bimedial rectus recession with retroequatorial myopexy are described and the development of alphabetical syndromes and dissociated vertical divergence discussed. The evolution of refraction in these cases is also shown.

Early treatment of strabismic amblyopia is no longer contested. Paradoxically, early strabismus surgery still meets with some controversy. Visual acuity and binocular functions do not evolve as a pair. Their development depends on there being no disturbance in the interaction between a maturation process which follows a genetic programme and visual experience which represents indispensable epigenetic influences.

Studies of the age at which adult-level visual acuity is achieved in normal infants give different results according to the testing techniques used. Results range from 4 to 6 months' and 4 years. ${ }^{2}$ Stereoacuity, however, is widely found to mature at an early age, from 3 to 6 months. ${ }^{2}$ Recent studies by Held et al. ${ }^{3}$ have shown that 'In comparison with the relatively slow development of visual acuity, the time course for the development of stereoacuity is extremely rapid.' This corroborates the conclusions of the neurophysiologist Vital-Durand ${ }^{4}$ whereby 'acuity follows rather than precedes the development of binocularity.' These findings correspond with my own clinical experience.

\section{Material and methods}

The first 82 cases of early-onset strabismus operated upon between the ages of 6 and 30 months have already been the subject of a previous publication. ${ }^{5}$ All 82 cases conform to the definition of pseudoparalysis of the lateral recti. Surgery is always symCorrespondence to Dr M Deller, Montbenon 2, 1003 Lausanne, Switzerland.
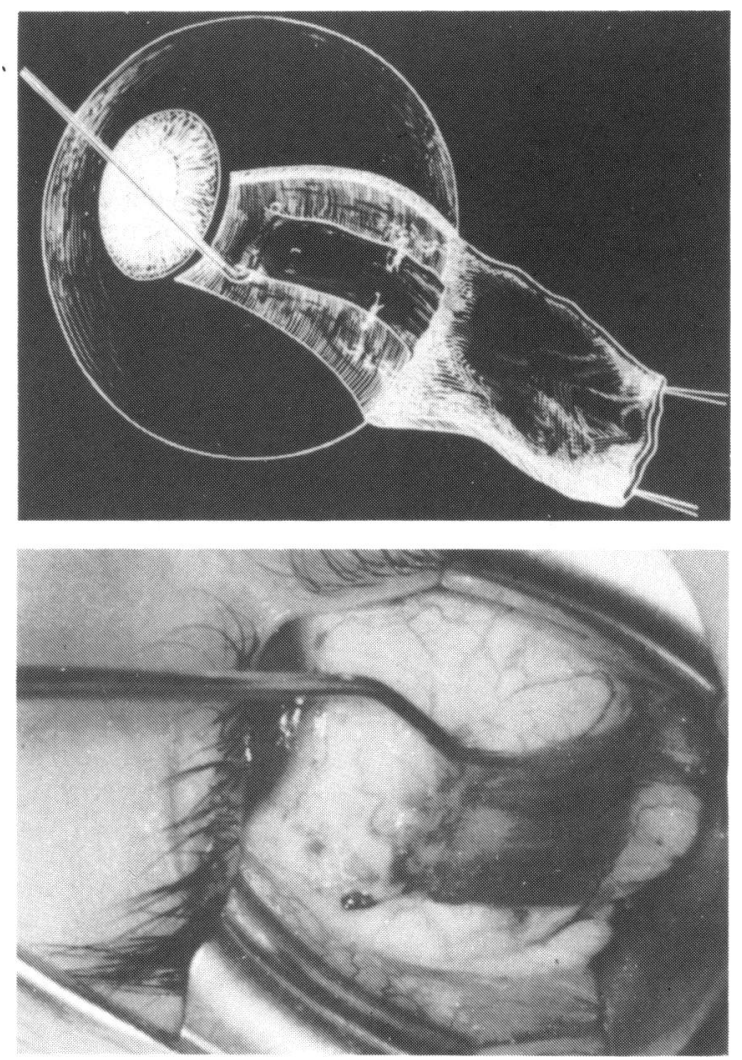

Fig. 1 Top: The retroequatorial myopexy-schematic diagram. Bottom: The retroequatorial myopexy-clinical appearance. 


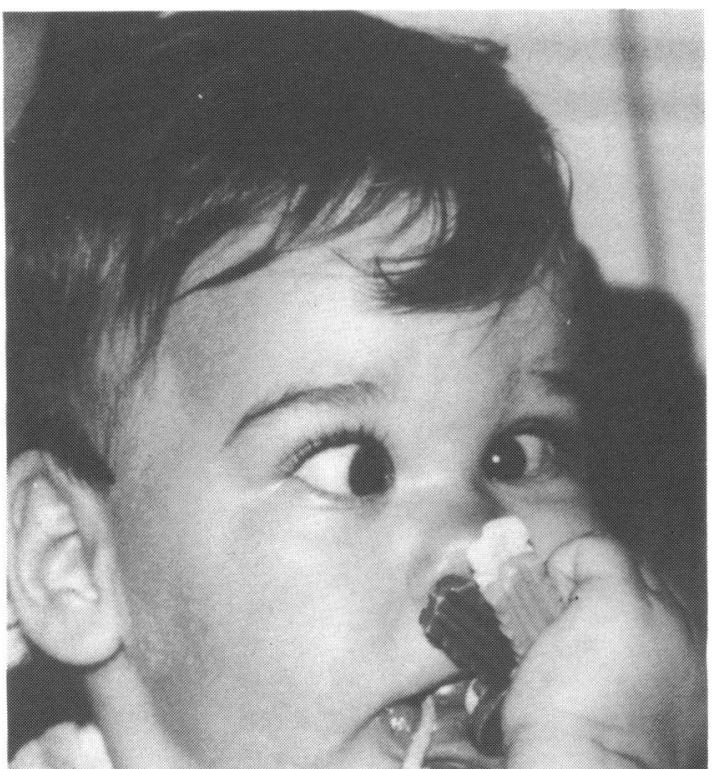

Fig. 2A Preoperative crossed fixation with abnormal head posture. Age 8 months.

metrical on the two medial recti, consisting of muscle recession with a retroequatorial myopexy. ${ }^{6}$ This operation is also known as 'Cüppers' faden operation' or 'posterior fixation suture', but I prefer the term, 'more precise though considered by some as too ponderous, retroequatorial myopexy' (von Noorden). ${ }^{7}$

Retroequatorial myopexy was introduced by Cüppers in Germany in 1974. The principle of this procedure is muscle anchorage to the sclera behind the equator (Fig. 1). This reduces the effective arc of contact between the muscle and the globe, thus selectively weakening the muscle in its field of action. There is no effect on the primary position or away from the muscle's field of action. The result of this surgery is reduction of the motor response, while the associated muscle recession corrects the eye position. The variability of the angle of deviation in this form of strabismus is well known. Surgery consisting of combined recession and retroequatorial myopexy permits a more appropriate correction than conventional surgical techniques. Far fewer immediate or late-occurring consecutive divergent deviations are observed, because the necessary muscle recession, when associated with the myopexy, is much smaller.

The myopexy is placed at $13 \mathrm{~mm}$ from the original muscle insertion. Exceptionally it may be placed at $12 \mathrm{~mm}$ in very small eyes. The associated muscle recession is $2 \mathrm{~mm}$ for deviations up to $25^{\circ}, 3 \mathrm{~mm}$ for those exceeding $25^{\circ}$.

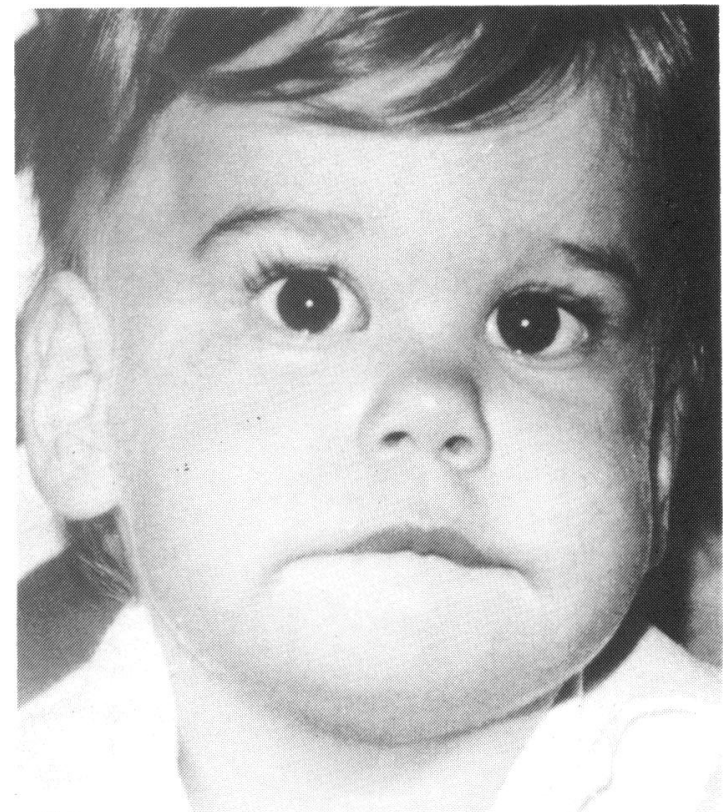

Fig. 2B Age 10 months-one week after surgery.

\section{Results}

The first study of these 82 cases gave ${ }^{5}$ the following results: excellent results concerning the angle of strabismus, with suppression of crossed fixation and the usual abnormal head posture, results showing notable stability with time (Figs. 2 and 3); immediate and complete recovery of abduction, satisfactory conjugate ocular movements, and good vergence; unblocking of amblyopia in a few cases refractory to preoperative treatment.

I have continued to follow up these 82 cases personally with the same two orthoptists. With the statistics brought up to date, there is a current minimum follow-up of at least one year where further surgery was necessary, and a maximum of 10 years. $80 \%$ of cases fall into the group of five years' minimum follow-up.

\section{MOTOR RESULTS \\ Horizontal angle of strabismus}

The latest postoperative angle of strabismus and the number of muscle procedures carried out are given in Table 1 . This shows that $72 \%$ of cases had a longterm angle of not more than \pm 10 prism dioptres (PD) after one single horizontal muscle surgical procedure.

Alphabetical syndromes and vertical (oblique) muscle surgery. Fourteen cases required further surgery because of alphabetical syndromes $(9 \mathrm{~V}, 4 \mathrm{~A}$, $1 \mathrm{X})$. The relative failure of single-step surgery was 


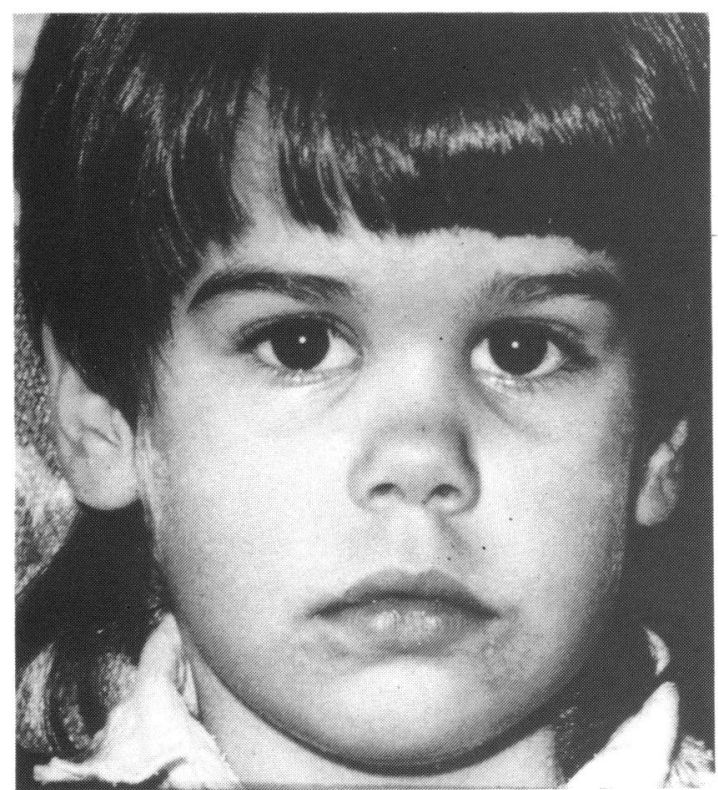

Fig. 2C Age 31/2 years.

thus mainly due to oblique muscle factors. Difficulty in diagnosing alphabetical syndromes in young infants is one argument used by those surgeons opposed to early surgery. In this first series of 82 cases purely horizontal muscle surgery was carried out in those infants under 20 months of age. Alphabetical syndromes in this group (11 cases out of 36) system-

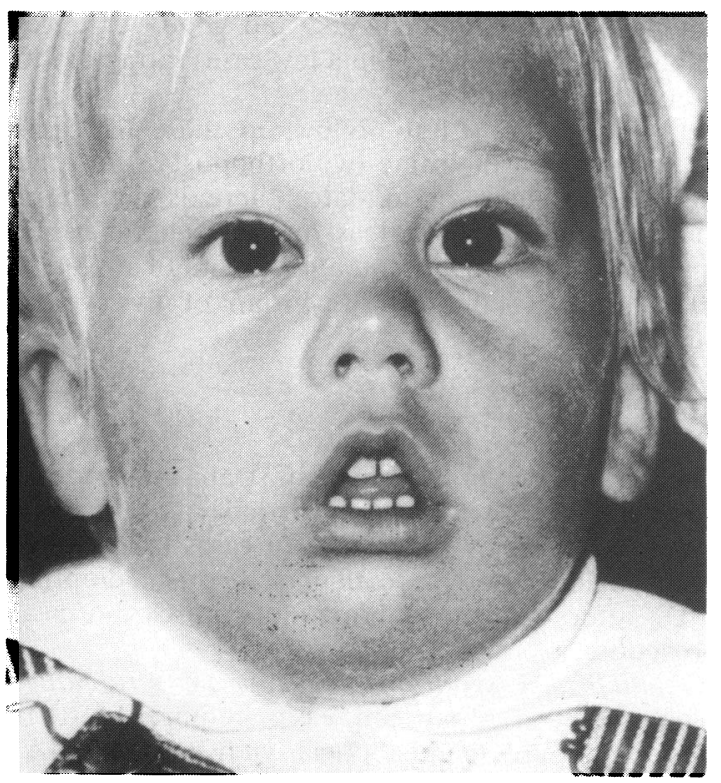

Fig. 3B Age 16months-one week after surgery.

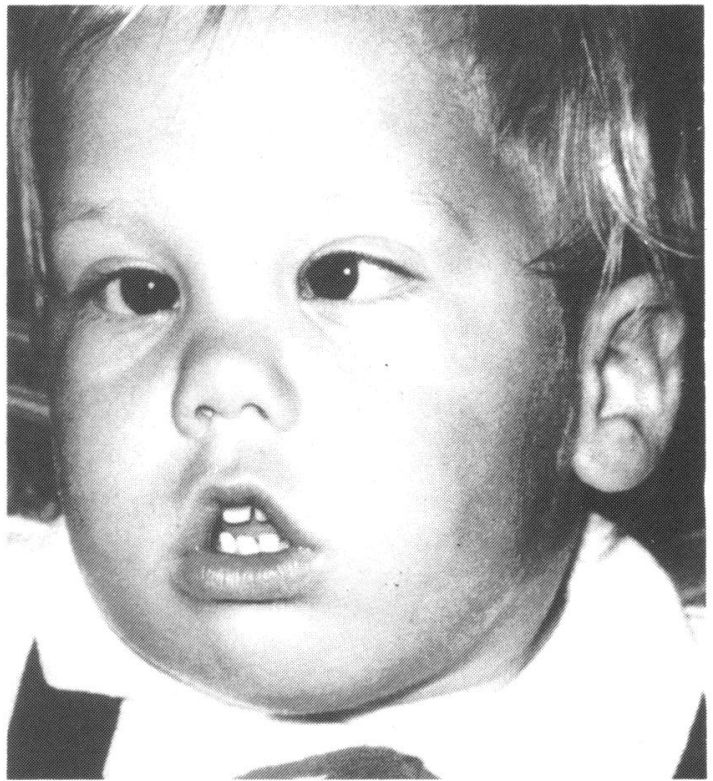

Fig. 3A Preoperative crossed fixation with abnormal head posture. Age 15 months.

atically underwent further surgery. In infants aged 21 to 30 months combined horizontal-vertical muscle surgery was carried out in seven cases, and only three required separate oblique muscle surgery. However, in a subsequent series of 70 cases with the same proportion of alphabetical syndromes combined horizontal-vertical muscle surgery was carried out in

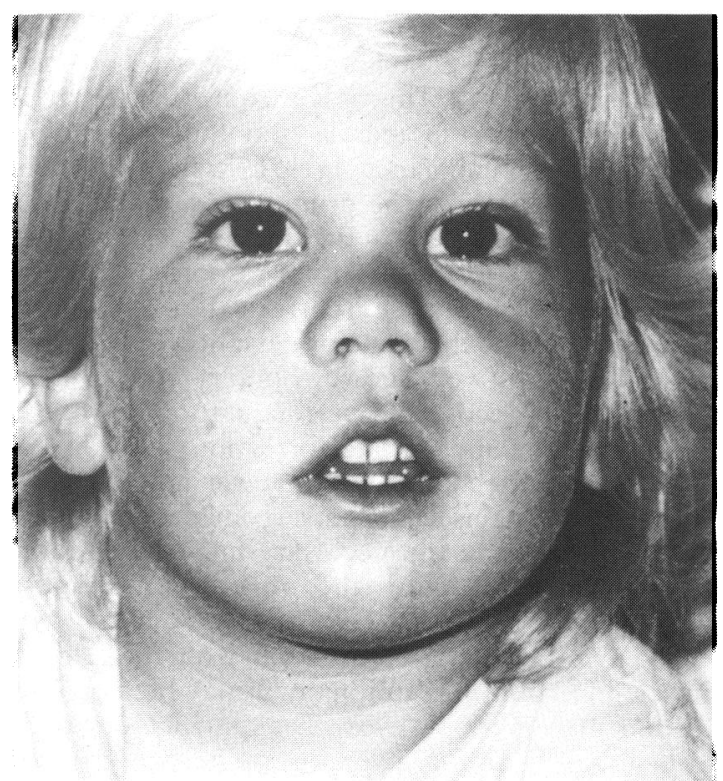

Fig. 3C Age 21/4years. 
Table 1 Long-term residual angle

\begin{tabular}{llllll}
\hline Angle $P D$ & \multicolumn{2}{l}{ Horizontal procedure } & & \multicolumn{2}{l}{ Horizontal procedures } \\
\cline { 2 - 3 } \cline { 5 - 6 } \cline { 5 - 6 } \cline { 5 - 6 } & No. cases & $\%$ & & No.cases & $\%$ \\
\hline Up to \pm 4 & 35 & 43 \\
$>4$ to \pm 10 & 24 & 29 \\
$>10$ & 18 & 22 & & 4 & 5 \\
\hline
\end{tabular}

a larger number of cases owing to more thorough examination even in the youngest age group, thus reducing the number of reoperations.

Alphabetical syndromes and age. $20 \%$ of cases presented an alphabetical syndrome before the age of 20 months, $36 \%$ between 20 and 30 months, according to our series of patients. Quéré, et al. ${ }^{8}$ noted them in $64 \%$ of cases and favoured postponement of surgery until $2 \frac{1}{2}$ to 3 years of age. Bérard" observed these syndromes in almost all cases, and considered 3 years as being the ideal age for surgery. It would thus appear that the vertical syndrome is secondary to a neglected horizontal deviation.

Dissociated vertical divergence (DVD). DVD was almost the rule ( $77 \%$ of cases), appearing at the earliest at 1 year, at the latest at 7 years, but in twothirds of cases between 2 and 4 years of age. As can be seen in Fig. 4, age at the time of surgery had no influence on the development of DVD. Cosmetically unsatisfactory decompensation of DVD requiring specific complementary surgery was necessary in only two cases, that is, $3 \%$ of the total number.

\section{REFRACTIONAL RESULTS}

The evolution of refractive error up to the age of 10 years in these 82 cases is shown in Fig. 5. Changes in refractive error followed essentially the same course as that described by Slapater ${ }^{11}$ and Brown, " where hypermetropia was shown to increase up to the age of 8 years, in contrast to Chavasse's findings. ${ }^{12}$ Thus early surgery consisting of bimedial recession with retroequatorial myopexy did not influence the evolution of refractive error.

\section{SENSORIAL RESULTS}

Our series of 82 cases is divided for closer study into six-monthly groups according to the patient's age at the time of surgery. The following criteria are required for positive binocular responses: 'coarse' stereopsis, moderate convergent and divergent fusion range, four dots on the Worth test, and crossed Bagolini striated glasses. The results are as given in Fig. 6. There is no question of real binocular single vision, even in cases of orthotropia. However, these figures show that the quality and frequency of binocular association diminished as the age at the time of surgery increased. The degree of residual angle (Fig. 7) was also an important factor in the acquisition of binocular association, but only on the following

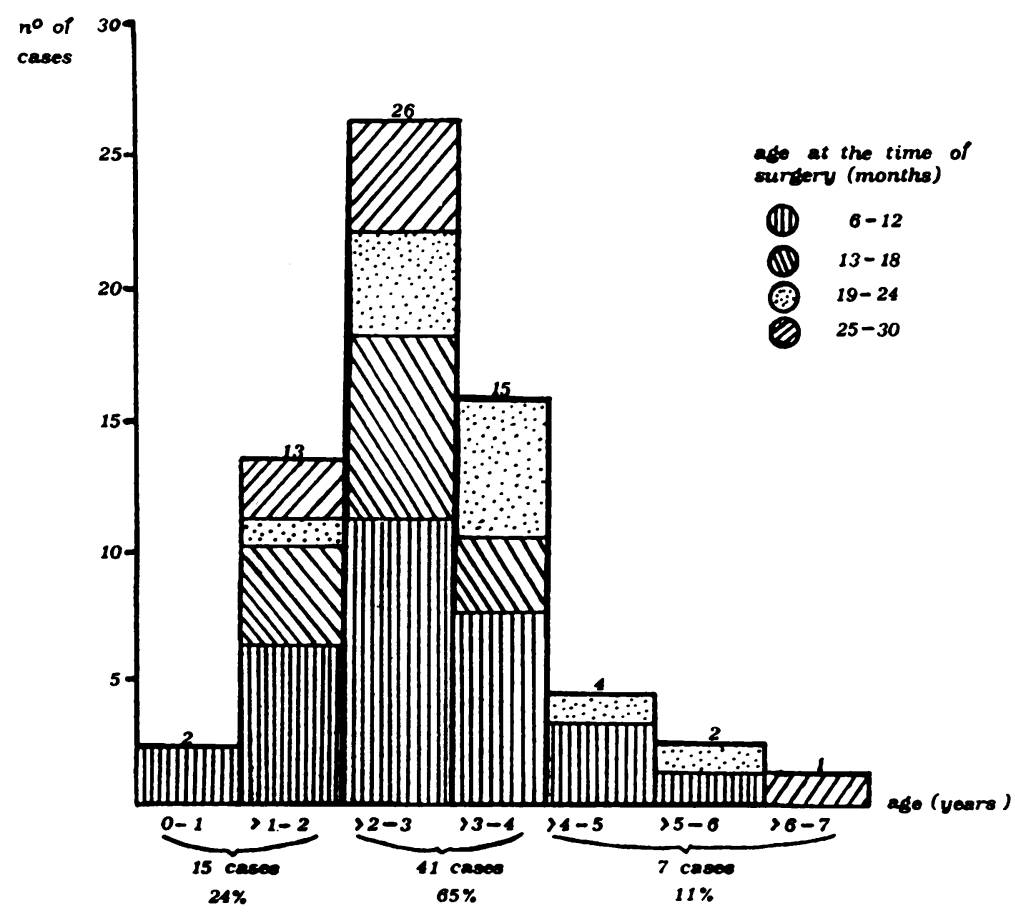

Fig. 4 Appearance of dissociated vertical divergence. 


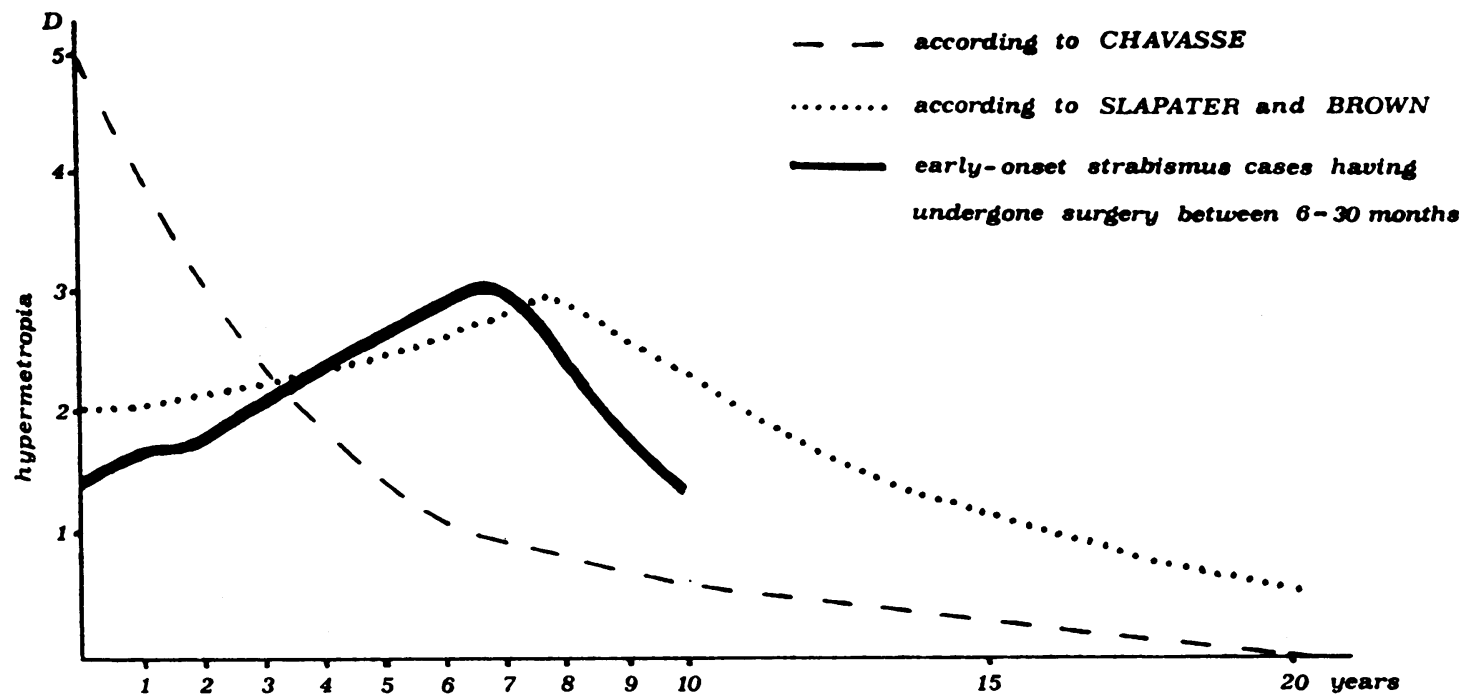

Fig. 5 Evolution of refractive error.

condition: the smallest residual angle is of any interest only for those patients having undergone surgery before the age of 1 year. Of the 13 cases with binocular association in the smallest angle group, 10 were operated upon between 6 and 12 months old, and one in each of the following six-month periods. Even in the larger-angle groups binocular association may be hoped for where surgery is carried out at a

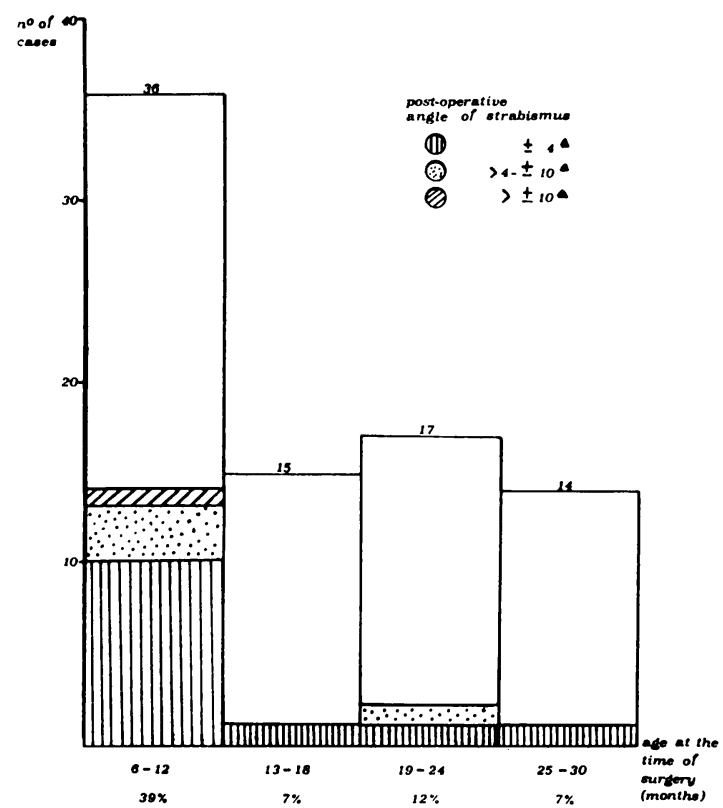

Fig. 6 Binocular responses according to age at time of surgery. very young age. These results confirm studies by Archer and associates ${ }^{13}$ in testing stereopsis, whereby 'the most striking feature was that the four patients with positive results were also the four youngest

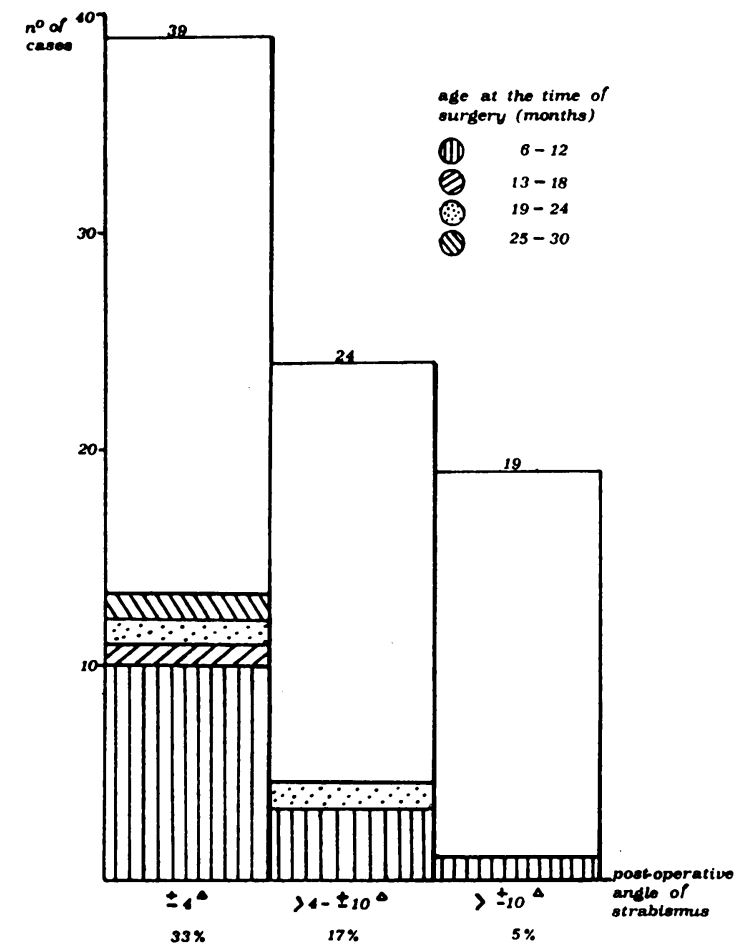

Fig. 7 Binocular responses according to postoperative angle of strabismus. 
infants at the time of surgery (ages ranging from 6 to 8 months).'

\section{Discussion}

In view of these findings it cannot be said that the functional results of early surgery are no better than those where surgery is postponed to around $2 \frac{1}{2}$ to 3 years of age. ${ }^{8}$ Our motor and sensorial results corroborate those given in studies by Mohindra et al. ${ }^{14}$ and Ing, ${ }^{15}$ where the limit of 24 months is fixed, beyond which a certain degree of stereoscopic vision may no longer be acquired if binocular coupling has had no occasion to be practised up to that time. I share Helveston's view where 'to our knowledge there is nothing to be gained from delaying surgery in a child who is considered a candidate for eventual surgical treatment. ${ }^{16}$ However, the latter's surgical protocol of 'en bloc' bimedial rectus recession ${ }^{17}$ is essentially compensatory at a time when the problem is primarily dynamic, and where passive elements are negligible. Although immediate alignment with such procedures is reported to be good at $82 \%,{ }^{16}$ up to $30 \%$ of these cases require further surgery for later occurring esotropia. In our series of 82 cases of bimedial rectus recession associated with retroequatorial myopexy, a single horizontal muscle procedure was found to be sufficient to obtain immediate and long-term alignment (to within \pm 10 PD) in $72 \%$ of cases, with no further surgery necessary.

In conclusion, these results are an indication not for early surgery but rather for immediate surgery, or surgery deferred only the short time necessary for preoperative treatment of any amblyopia. Indeed, why postpone surgery for early-onset strabismus?

I thank my orthoptist, Miss S E Houghton, for her help in the preparation and translation of this paper.

\section{References}

1 Marg E, Freeman DN, Peltzman P, Goldstein PJ. Visual acuity development in human infants: evoked potential measurements. Invest Ophthalmol Vis Sci 1976; 15: 150-3.

2 Gwiazda JE, Birch EE, Held R. Le développement de la vision chez l'enfant. Recherche 1981; 12: 1348.

3 Held R, Birch E, Gwiazda J. Stereoacuity of human infants. Proc Natl Acad Sci USA 1980; 77: 5572-4.

4 Vital-Durand F. Données nouvelles sur le système visuel. 2e partie: Développement et plasticité des voies visuelles. $J$ Fr Ophthalmol 1983; 6: 319-23.

5 Deller M. Single surgical procedure in the management of pseudo-paralysis of the lateral recti. In: Boschi MC, Frosini R, eds. Strabismus. Proceedings of the International Symposium on Strabismus. Florence: Consilium Europaeum Strabismi Studio Deditum, 1982: 503-7.

6 Deller M. Les techniques de l'opération du fil. J Fr Orthoptique 1978; 10: 89-96.

7 Von Noorden G. Binocular vision and ocular motility. St Louis: Mosby, 1980: 455.

8 Quéré MA, Pechereau A, Lavenant F. Etude statistique de l'angle de base et de l'intensité du spasme dans les ésotropies fonctionelles (conséquences chirurgicales). J Fr Ophtalmol 1985; 8: 255-61.

9 Bérard PV. In: Bérard PV, Quéré MA, Roth A, Spielman A, Woillez M, eds. Chirurgie des strabismes. Paris: Masson, 1984: 248.

10 Slapater FJ. Age norms of refraction and vision. Arch Ophthalmol 1950; 43: 466-81.

11 Brown EVL. Net average yearly changes in refraction of atropinized eyes from birth to beyond middle life. Arch Ophthalmol 1938; 19: 719.

12 Chavasse B. In: Worth and Chavasse's squint. 8th ed. London: Baillière, Tindall and Cox, 1950: 23.

13 Archer SM, Helveston EM, Miller KK, Ellis FD. Stereopsis in normal infants with congenital esotropia. Am J Ophthalmol 1986; 101: 591-6.

14 Mohindra I, Zwaan J, Held R, Brill S, Zwaan F. Development of acuity and stereopsis in infants with esotropia. Opththalmology 1985; 92: 691-7.

15 Ing MR. Surgical alignment for congenital esotropia. Controversies 1984; 21 : 76-7.

16 Helveston EM. Options in the treatment of congenital infantile esotropia. Trans Ophthalmol Soc UK 1983; 103: 139-42.

17 Helveston EM. Atlas of strabismus surgery. St Louis: Mosby, 1977: 211.

Accepted for publication 15 December 1986. 